\title{
Some Diseases of Cotton as seen in the Plantations. ${ }^{1}$
}

] $\mathrm{N}$ order to facilitate research work being carried out in the University of Manchester, for the Empire Cotton Growing Corporation, a visit was paid to some of the cotton states of America in the summer of 1924. The diseases of cotton described were observed in the plantations of North and South Carolina. In that season, according to recently published estimates by the U.S. Department of Agriculture, fungal and bacterial diseases of cotton reduced the crop in the U.S.A. by $1,900,000$ bales. The extent of these losses in what was a relatively favourable season for cotton-growing indicates the importance of these diseases.

In the United States some diseases are more important than others, but, at the present time, all of them may be important to Great Britain in view of the considerable extension of cotton-growing in progress in various parts of the British Empire. In some of these countries a new crop plant is being introduced; we have little knowledge how it will react to its new environment and we do not know what diseases will appear. It is certain, however, that some diseases will occur, and it is well known that a disease which is relatively harmless in one country may become destructive in another. This may be illustrated by some of the diseases seen in the United States. Bacterium malvacearum causes the angular leaf spot and a boll disease on Upland varieties of cotton (Gossypium hirsutum), the leaves and bolls usually being the only parts of the plant affected. The Sea Island and Egyptian varieties of cotton ( $G$. barbadense and $G$. peruvianum) are much more susceptible to the attacks of the organism, which also affects the leaf-stalks and branches, causing the " black arm " form of the disease. This " black arm " disease is already causing serious concern in the Sudan on Egyptian cotton, although in Egypt, presumably on account of the different climatic conditions, it is not troublesome. It is now known that infection may be carried on the seed, and seeddisinfection has proved successful in preventing the disease in the United States.

Again, in the U.S.A. several root-diseases of cotton

1. Substance of paper read before the Mancliester Literary and Philosophical Society by Dr. Wilfrid Robinson on December 8 . occur. Of these the Texas root-rot (Ozonium) and the wilt disease caused by Fusarium vasinfectum are of most importance. In the latter case the disease was studied in South Carolina on badly infected soils. The fungus present in the soil passes into the conducting tissues of the plant and, excreting poisonous substances, leads to dwarfing, wilting and killing of the whole plant. In the Sudan a rootdisease (the Tokar root-rot), undoubtedly different from the Fusarium wilts or Texas root-rot, but capable of stunting and killing the plant by progressive infection, is also causing trouble. Work at present in progress on this disease should ultimately determine its cause and probably provide for its control.

Diseases of the immature or opened bolls are commonly caused in the U.S.A. by Glomerella gossypii (anthracnose disease), Fusarium, Diplodia, and by Bacterium malvacearum. The cotton lint is destroyed, weakened or discoloured by such organisms. Similar boll diseases occur wherever cotton is grown, and recent studies by Mr. R. W. Marsh on discoloured cotton from Nyasaland have shown that the yellow discoloration is due to a species of Nematospora, a fungus. In the West Indies this fungus has been shown by Nowell to be inoculated into the bolls by cotton stainer bugs, which puncture the bolls as they feed. Stainer bugs were observed feeding on cotton bolls in South Carolina, but up to the present the Nematospora fungus is not known to cause disease of cotton in the U.S.A.

Other diseases of cotton studied were those caused by species of Alternaria and Ascochyta gossypii. These have not hitherto been of serious consequence in the United States, but the latter is now spreading and both diseases may prove much more harmful in other countries.

Of the diseases to which reference has been made, several have as yet been imperfectly studied, and only by extended work on such diseases and on the organisms responsible for them will it be possible for the growers and plant pathologists in cotton countries to guard against outbreaks of disease and to devise satisfactory means of control when such outbreaks occur.

\section{Causes of Volcanic Activity.}

( $\mathrm{N}$ the occasion of the centenary of the Franklin Institute in 1924, Dr. A. L. Day delivered an address on volcanic activity, which appears in the journal of the Institute for August 1925. It is well known that the crater of Mauna Loa is ro, ooo feet higher than the lava lake of Kilauea. Since more lava emerges from the higher vent than the lower, and eruptions rarely occur simultaneously, it is clear that the two vents cannot be connected with a continuous liquid interior. The changes of level of the lava of Kilauea would show'periodic tidal effects if there were a molten cauldron underneath, but they fail to do so. Moreover, the lava lake was recently drained to a depth of 1500 feet, and a solid relatively cold bottom was exposed. A number of channels leading in from below were detected on the side walls.

Another firmly established conclusion is that the varying temperatures and fluidity of the lava are due to irregular uprisings of gases. These have evidently come from isolated chambers in which crystallisation is approaching completion, but at different stages from place to place. The gases pass up through various channels into the central basin, where they meet and react, and so produce the heat necessary to maintain the superficial vulcanism. The gases actually collected from the lava include hydrogen, chlorine, and sulphur, which, in association with others, make an unstable mixture that could not have come from any single source, since it is in a state of active exothermic reaction.

Modern volcanoes thus appear to be controlled by the liberation of gases from a crystallising mass below, and are very different phenomena from the fissure eruptions that gave rise to the great basalt plateaux of the Deccan and the Brito-Arctic region. The conclusion is amply confirmed by the study of the recent explosions of Lassen Peak, which were essentially due to the release of steam from a closed chamber of crystallising magma beneath the crater. Practically no chemically active gases were discharged, and consequently the temperature remained much lower than at Kilauea, and no lava was emitted.

No other North American volcano, and few in the whole world, have been investigated so thoroughly as Lassen Peak, and the magnificent memoir by Dr. A. L. Day and Dr. E. T. Allen (Carnegie Inst. of Washington,

NO. 2932, VOL. II7] 